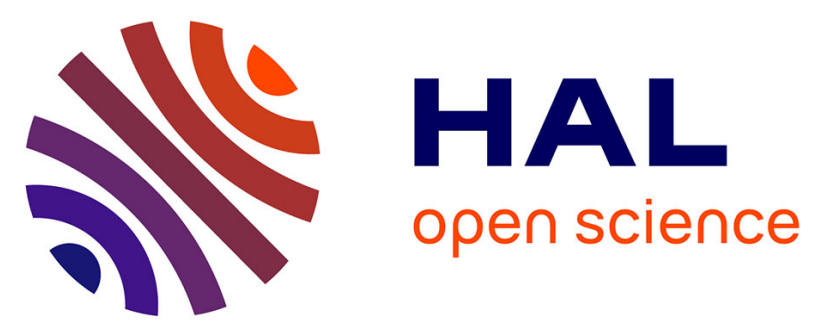

\title{
Fatigue behavior of a structural steel coated with a WC-10Co-4Cr/Colmonoy 88 deposit by HVOF thermal spraying
}

\author{
José Gregorio La Barbera-Sosa, Y.Y. Santana, C. Villalobos-Gutierrez, D. \\ Chicot, J. Lesage, X. Decoopman, Alain Iost, M.H. Staia, Eli Saúl \\ Puchi-Cabrera
}

\section{To cite this version:}

José Gregorio La Barbera-Sosa, Y.Y. Santana, C. Villalobos-Gutierrez, D. Chicot, J. Lesage, et al.. Fatigue behavior of a structural steel coated with a WC-10Co- $4 \mathrm{Cr} / \mathrm{Colmonoy} 88$ deposit by HVOF thermal spraying. Surface and Coatings Technology, 2013, 220, pp.248-256. 10.1016/j.surfcoat.2012.05.098 . hal-01070169

\section{HAL Id: hal-01070169 \\ https://hal.science/hal-01070169}

Submitted on 10 Oct 2017

HAL is a multi-disciplinary open access archive for the deposit and dissemination of scientific research documents, whether they are published or not. The documents may come from teaching and research institutions in France or abroad, or from public or private research centers.
L'archive ouverte pluridisciplinaire HAL, est destinée au dépôt et à la diffusion de documents scientifiques de niveau recherche, publiés ou non, émanant des établissements d'enseignement et de recherche français ou étrangers, des laboratoires publics ou privés. 


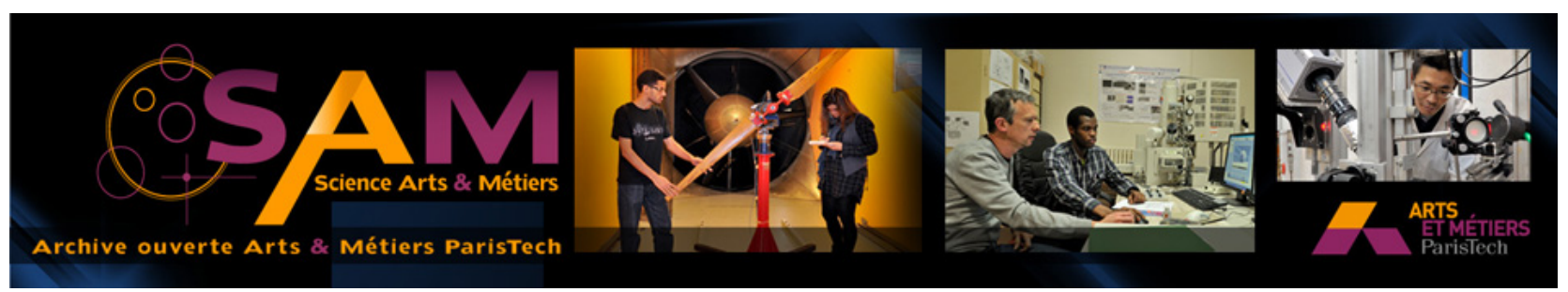

\section{Science Arts \& Métiers (SAM)}

is an open access repository that collects the work of Arts et Métiers ParisTech researchers and makes it freely available over the web where possible.

This is an author-deposited version published in: http://sam.ensam.eu

Handle ID: .http://hdl.handle.net/10985/8663

\section{To cite this version :}

J.-G. LA BARBERA-SOSA, Y.Y. SANTANA, C. VILLALOBOS-GUTIERREZB, D. CHICOT, J. LESAGE, X. DECOOPMAN, Alain IOST, M.H. STAIA, E.S. PUCHI-CABRERA - Fatigue behavior of a structural steel coated with a WC-10Co-4Cr/Colmonoy 88 deposit by HVOF thermal spraying - Surface and Coatings Technology - Vol. 220, p.248-256 - 2013 


\title{
Fatigue behavior of a structural steel coated with a WC-10Co-4Cr/Colmonoy 88 deposit by HVOF thermal spraying
}

\author{
J.G. La Barbera-Sosa a,*, Y.Y. Santana a , C. Villalobos-Gutiérrez ${ }^{\text {b }}$, D. Chicot ${ }^{\text {c }}$, J. Lesage ${ }^{\text {c }}$, X. Decoopman ${ }^{\text {c }}$, \\ A. Iost ${ }^{\mathrm{c}}$, M.H. Staia ${ }^{\mathrm{a}}$, E.S. Puchi-Cabrera ${ }^{\mathrm{a}, \mathrm{c}, \mathrm{d}}$ \\ a School of Metallurgical Engineering and Materials Science, Faculty of Engineering, Universidad Central de Venezuela, Caracas, Venezuela \\ b School of Mechanical Engineering, Faculty of Engineering, Universidad Central de Venezuela, Caracas, Venezuela \\ c Université Lille Nord de France, USTL, LML, CNRS, UMR 8107, F-59650 Villeneuve d'Ascq, France \\ d Venezuelan National Academy for Engineering and Habitat, Palacio de las Academias, Postal Address 1723, Caracas 1010, Venezuela
}

Keywords:

Fatigue

Nanoindentation

WC-Co-Cr

Colmonoy 88

Coating

HVOF

\begin{abstract}
A B S T R A C T
The fatigue behavior of a SAE 4340 steel, coated with a 50\% WC-10Co-4Cr/50\% Colmonoy 88 deposit, by high velocity oxygen fuel (HVOF) thermal spray, has been investigated. The change in the maximum alternating stress with the number of cycles to fracture has been described by means of the relationship advanced by Stromeyer. A fractographic analysis has been carried out on some representative fracture surfaces, by means of scanning electron microscopy (SEM) techniques. The mechanical properties of the coating were characterized by means of nanoindentation tests. The results indicate that the coating is highly heterogeneous. Its deposition gives rise to a decrease in the fatigue strength of the substrate of $\sim 30 \%$, in comparison with the uncoated substrate. The decrease in fatigue strength is due to the presence of stress concentrators at the substrate-coating interface, as well as the intrinsic characteristics of the coating.
\end{abstract}

\section{Introduction}

The aeronautic industry constitutes an important application field of thermal sprayed coatings, particularly as far as dynamic components for planes and helicopters are concerned. These structural elements include, transmission parts and rotor heads, internal cylinders for landing gear, shafts, hydraulic actuators, gas turbine engines components, etc. [1,2]. For these applications, structural aluminum alloys and steels with high strength, toughness and fatigue properties are commonly employed, whose resistance to sliding, and abrasive and fretting wear can be increased by means of adequate coatings.

However, such an improvement in the tribological properties could give rise to a significant decrease in the fatigue life of the coated components, such as it has been found in many different parts coated with electrolytic hard chromium (EHC) plating. Although such a coating gives rise to an improvement in the substrate wear resistance, it occurs at the expense of a decrease in the fatigue performance, in comparison to the uncoated parts [3-10]. Therefore, the qualification of a thermal spray coating employed as a feasible replacement of EHC requires the evaluation of the effect of such a coating on the fatigue properties of the substrate, particularly in critical components such

\footnotetext{
* Corresponding author. Fax: +58 2126051492

E-mail addresses: jose.labarbera@ucv.ve, joselabarbera@gmail.com
} (JG. La Barbera-Sosa). as aircraft engines, for which high cycle fatigue represents the most important failure mechanism [11,12].

Thus, it is expected that the deposition of the coating does not give rise to any decrease in fatigue properties or, at least, if a fatigue debit is induced, it should not be greater than that produced by EHC $[1,5,6]$. In this sense, a number of investigations have shown that although WC-Co and WC-Ni coatings deposited by HVOF thermal spray give rise to a decrease in the fatigue properties of 4340 steel substrates, it is less than that produced by EHC [8,9,13-15].

In relation to Ni-base self-fluxing coatings deposited onto medium carbon structural steels, previous work has shown an increase in the fatigue strength of the coated system in comparison with that of the uncoated substrate, particularly when tests are conducted in a corrosive medium [16-21]. However, if the tests are conducted in the air, the decrease in fatigue strength could be greater than that produced by WC-Co coatings $[22,23]$.

Flame post-heat treatments have also been employed to modify the microstructure of self-fluxing coatings and therefore, the fatigue properties of the coated systems. In this sense, Akebono et al. [24], conducted an investigation of such a treatment on a Ni-base alloy (Ni-13.7Cr-2.96B-4.40Si-2.67Fe-0.60C; wt.\%), deposited onto an AISI 1036 steel substrate. The deposition was conducted by flame spray, employing a mixture of oxy-acetylene, a spraying distance of $200 \mathrm{~mm}$ and a coating thickness of $1.5 \mathrm{~mm}$. Post-heat treatments were conducted in a vacuum for $0.5,4$ and $10 \mathrm{~h}$, at a temperature of $1283 \mathrm{~K}$. Rotating bending fatigue tests were carried out at room temperature at a frequency of $50 \mathrm{~Hz}$, employing samples in which the 
coatings were machined to $1 \mathrm{~mm}$ in thickness, heat-treated and polished in a similar way to that of the uncoated substrate specimens.

The results indicated that the fatigue properties of the coated systems were significantly dependent on the size and distribution of the porosity present in the coating, as well as on the hardness of the $\mathrm{Ni}$ rich matrix. The shortest heat-treatment gave rise to the best fatigue performance due to the least amount of porosity, in comparison with the other heat-treatment times. Also, after $10 \mathrm{~h}$ of treatment, precipitation and coarsening of $\mathrm{Cr}$-rich compounds resulted in a decrease of the coating matrix hardness. In addition, it was observed that fatigue cracks propagated preferentially through the matrix, which explained the decrease in fatigue properties as the matrix hardness decreases.

Thus, the present investigation has been carried out in order to study the mechanical properties of a composite coating made from the mixture of $\mathrm{WC}-10 \mathrm{Co}-4 \mathrm{Cr}$ powders with a Ni-base self-fluxing alloy and to analyze the fatigue behavior of the coated system, in comparison with that of the uncoated substrate. The fatigue results are further compared with those observed for the same substrate when it is coated with either WC-12Co or Colmonoy also by HVOF thermal spraying.

\section{Experimental techniques}

\subsection{Substrate alloy and specimens preparation}

The present investigation was carried out employing samples of a SAE 4340 quenched and tempered (Q\&T) steel, with the following chemical composition (wt.\%): $0.41 \mathrm{C}, 1.65 \mathrm{Ni}, 0.79 \mathrm{Cr}, 0.69 \mathrm{Mn}, 0.25$ Mo, $0.24 \mathrm{Si}, 0.024 \mathrm{P}$ and $0.011 \mathrm{~S}$. The material was provided in the form of bars $25.4 \mathrm{~mm}$ in diameter and $8 \mathrm{~m}$ in length. A number of parallelepiped samples with a dimension of $20 \times 20 \times 8 \mathrm{~mm}^{3}$ were machined and subsequently coated and used for the nanoindentation tests. The characterization of the initial powders and coating involved the analysis of their microstructure by means of SEM techniques, both in secondary (SE) and back-scattered electron (BSE) modes, employing for this purpose a Hitachi S-2400 microscope with EDS analytical facilities.

Hour-glass fatigue samples $38.1 \mathrm{~mm}$ in gage length and $58.74 \mathrm{~mm}$ in radius were machined according to the ASTM E 606 standard. The smallest diameter of the gage section was $6.35 \mathrm{~mm}$, with shoulders $31.75 \mathrm{~mm}$ in length and $12.7 \mathrm{~mm}$ in diameter.

\subsection{Coating and spraying conditions}

The deposited coating consisted of a powder mixture of 50\% WC$10 \mathrm{Co}-4 \mathrm{Cr}$ (Sulzer Metco 5847, Sulzer Metco) and 50\% of NiWCrSiFeB alloy (Colmonoy 88, Wall Colmonoy). According to the supplier, the powders have a nominal particle-size distribution of $11-53 \mu \mathrm{m}$ and 22-62 $\mu \mathrm{m}$, respectively. The powders were mixed in two steel containers coated internally with Colmonoy 88 , employing WC balls and ethyl alcohol, in order to assist the mixing process. For this purpose, a Cole Palmer LABMILL 8000 equipment was employed, which rotated at 47 r.p.m. for $45 \mathrm{~min}$. Subsequently, the mixture was heated to $40{ }^{\circ} \mathrm{C}$ for the evaporation of the alcohol and the drying of the mixed powder. The deposition of the coating was carried out both onto the parallelepiped and fatigue samples, which were degreased with an organic solvent mixture and pre-heated to eliminate their humidity prior to deposition. Subsequently, the specimens were grit blasted with an alumina of $0.3-1 \mathrm{~mm}$ size range, at a pressure of $0.4 \mathrm{MPa}$ and a distance of $150 \mathrm{~mm}$.

HVOF deposition was conducted employing a Praxair-TAFA JP5000 gun under the following conditions: spraying distance of $406 \mathrm{~mm}$, powder feeding rate of $83 \mathrm{~g} \mathrm{~min}^{-1}$, kerosene flux of $231 \mathrm{~min}^{-1}$ and oxygen flux of $781 \mathrm{~min}^{-1}$. The final temperature of the specimens was of $\sim 80^{\circ} \mathrm{C}$.

\subsection{Nanoindentation tests}

Nanoindentation experiments were performed using an MTS nanoindenter equipped with a Berkovich indenter. The values of the loading and unloading rates (expressed in $\mathrm{mN} \mathrm{min}^{-1}$ ) were set at twice the value of the maximum applied load, according to the rule proposed by Quinn et al. [25]. A dwell-time of $15 \mathrm{~s}$ was imposed according to the standard indentation test procedures of ASTM E92 and E384-10e2. During the indenter loading, the continuous stiffness measurement (CSM) mode was applied for the determination of the continuous contact hardness, $\mathrm{H}_{\mathrm{IT}}$, and the elastic modulus of the material, E. 20 indentation experiments were performed randomly at the surface of the coating, which was polished prior to testing, to a mirror-like finish, with a mean surface roughness $\left(R_{a}\right)$ of $0.09 \pm$ $0.01 \mu \mathrm{m}$. Such a surface roughness was determined by means of white light optical interferometry (Zygo New View 200) whose lateral and vertical resolutions are 0.7 and $0.01 \mu \mathrm{m}$, respectively. During the characterization of the mechanical properties of coated systems by instrumented indentation, it is well-recognized that the influence of the substrate begins to be noticeable at indentation depths close to $10 \%$ of the film thickness, depending on the hardness and the nature of the film [26-29]. On the other hand, for the determination of the elastic modulus, this value is reduced to $1 \%[30,31]$. In this study, in which the coating thickness of the parallelepiped samples was equal to $700 \pm 30 \mu \mathrm{m}$, the maximum depth reached by the indenter must be limited to $8 \mu \mathrm{m}$, in order to avoid the use of models which allow the separation of the influence of the substrate in the hardness and the elastic modulus determination. In the present study, the maximum displacement reached by the Berkovich indenter was $2 \mu \mathrm{m}$.

\subsection{Fatigue tests in air}

The coated fatigue samples were tested in the as-deposited condition, without any further surface polishing. Their surface roughness $\left(R_{a}\right)$ was determined by means of white light interferometry techniques and it was found to be $6.40 \pm 0.90 \mu \mathrm{m}$. Fatigue tests were conducted under rotating bending conditions employing Fatigue Dynamics RBF-200 equipment. The fatigue strength was evaluated between $10^{5}$ and $10^{6}$ cycles to fracture, that is to say, under highcycle fatigue conditions. Four different maximum alternating stress levels in the range of 410 to $470 \mathrm{MPa}$ were employed and four samples were tested at each stress level. The tests were conducted at a frequency of $50 \mathrm{~Hz}$.

The maximum alternating stress was determined as a function of the bending moment applied to the specimen by means of the classical relationship:

$M_{B}=\frac{\pi}{32} \sigma_{a} d^{3}$

where $M_{B}$ represents the bending moment in $\mathrm{Nmm}, \sigma_{a}$ the maximum alternating stress in MPa and $d$ the diameter of the coated specimen in $\mathrm{mm}$.

The change in the maximum alternating stress with the number of cycles to fracture has been described by means of the relationship advanced by Stromeyer [32]:

$\sigma_{a}=\sigma_{L}+\left(\frac{N_{f}}{K}\right)^{-m}$

In the above relationship, $\sigma_{L}$ represents the fatigue limit and $K$ and $m$ are constants, which depend on the material, loading type and shape and dimensions of the sample. The constants $\sigma_{L}, K$ and $m$ are determined from the experimental values of the maximum alternating stress $\left(\sigma_{a}\right)$ and the number of cycles to fracture $\left(N_{f}\right)$ by means of least-square methods. 

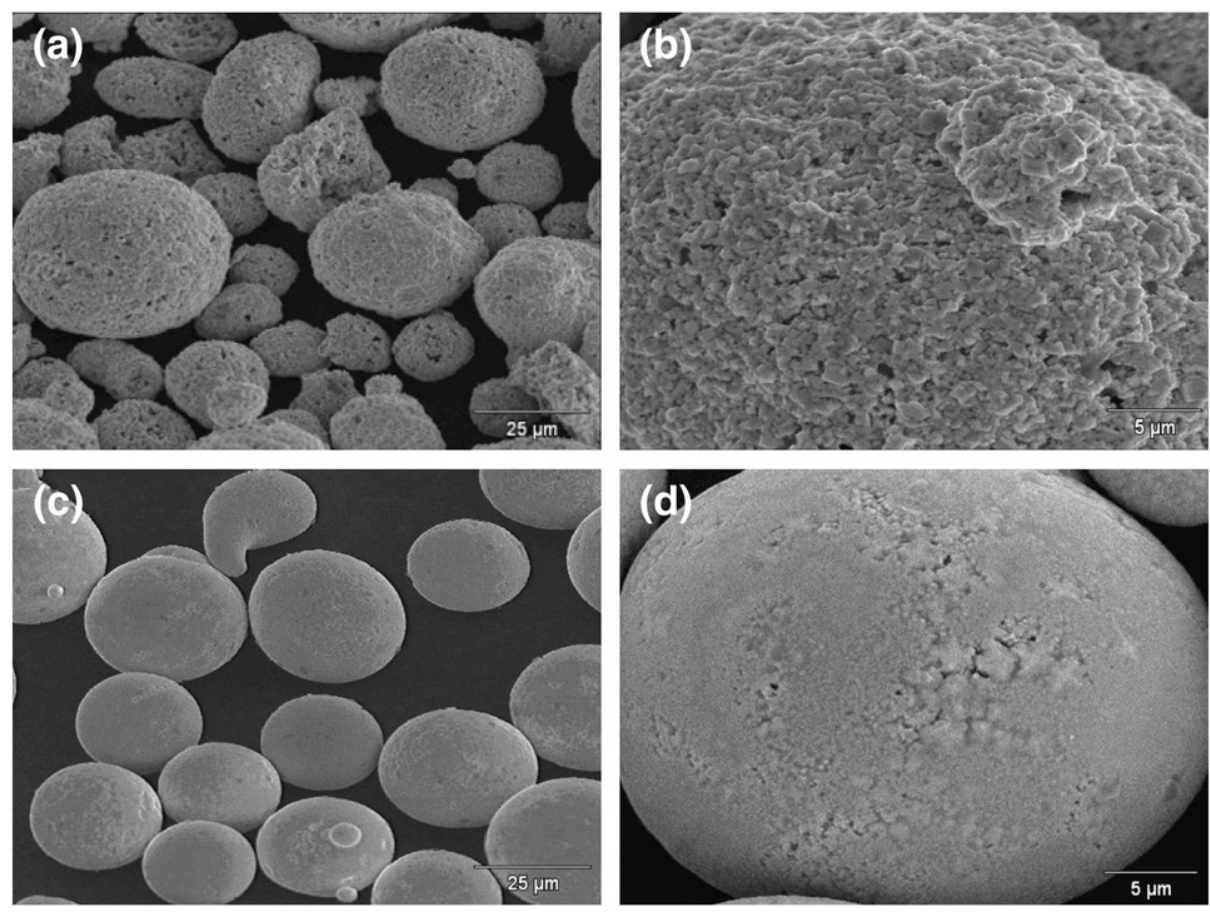

Fig. 1. SEM (SE) photomicrographs illustrating the morphology of the WC-10Co-4Cr (a and b) and Colmonoy 88 (c and d) initial powders.

Finally, a fractographic analysis of some selected samples tested at the highest and lowest maximum alternating stresses was carried out employing SEM-EDS techniques. Such a study was conducted both on the fracture surface of the specimens and on the sections normal to these specimens, with the aim of determining both the fractographic features of the fracture surface and the initiation and propagation sequence of the fatigue cracks.

\section{Experimental results}

\subsection{Characteristics of the initial powders and coating}

Fig. 1 illustrates the main characteristics of the powders employed for the deposition of the coating. Fig. 1a shows the size distribution of the WC-Co-Cr particles, which ranges approximately between 10 and $40 \mu \mathrm{m}$. The particles have a quasispherical morphology, as a consequence of the manufacturing process, which involves both their agglomeration and sintering. Fig. 1b illustrates at a higher magnification $(4000 \times)$ one of the powder particles, which is characterized by an irregular surface associated with the WC faceted morphology. Also, in Fig. 1c, the size distribution of the Colmonoy 88 particles can be observed. Most of these particles have a quasispherical morphology and a similar size, as a consequence of the atomization process employed for their manufacture. It was determined that the mean diameter of these particles was $30 \pm 4 \mu \mathrm{m}$. Fig. 1d illustrates a detail of a Colmonoy 88 particle in which the presence of second-phase particles with different morphologies can be observed. Star-like particles and other finely dispersed and smaller particles present in the Ni matrix can be clearly observed. Such particles are associated with the presence of Cr-rich tungsten carbides and/or borides, as well as $\mathrm{W}$ and $\mathrm{Ni}$ borides and/or carbo-borides [33,34].

Fig. 2a illustrates the general microstructural features of the deposited coating, where two different contrasts can be observed. The regions with a clear contrast are associated with the $\mathrm{WC}-10 \mathrm{Co}-4 \mathrm{Cr}$ particles, whereas the regions with a darker contrast are associated with the Colmonoy 88 particles. Also, it can be clearly seen that both materials are heterogeneously distributed in volume fractions closely similar throughout the entire coating. The particles of both materials that constitute the coating are observed to exhibit some preferential orientation, which is closely parallel to the substratecoating interface. The coating deposited onto the fatigue specimens has a thickness of $130 \pm 20 \mu \mathrm{m}$.

Fig. 2a also shows that the substrate-coating interface is quite irregular, as well as the presence of dark particles of different sizes embedded in the matrix, such as that indicated in the photomicrograph as $\mathrm{A}$, which is constituted by alumina particles employed in the grit blasting process. Fig. $2 \mathrm{~b}$, on the other hand, illustrates, at a larger magnification, a region close to the alumina particle identified as $\mathrm{A}$ in Fig. 2a, whereas in Fig. 2c a detail of the coating corresponding to the Colmonoy particles is shown. Here, two different zones, B and C, with second-phase particles of different sizes can be clearly observed. Zone $\mathrm{B}$ was found to be rich in $\mathrm{Ni}$ and $\mathrm{Cr}$, with quadrilateral shaped
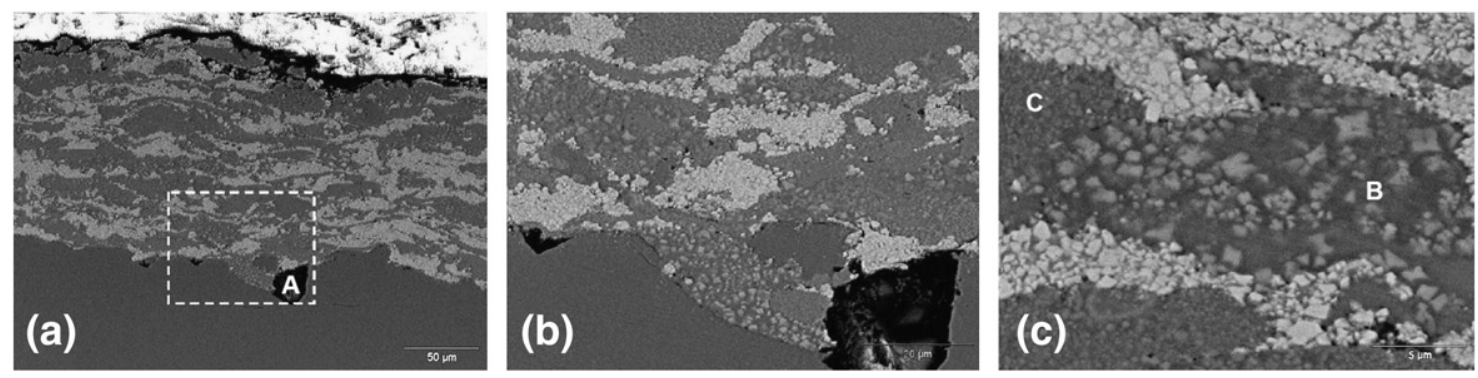

Fig. 2. SEM (BSE) photomicrographs showing the microstructural characteristics of the coating and substrate-coating interface. (a) $400 \times$, (b) $1500 \times$ and $(c) 5000 \times$. 


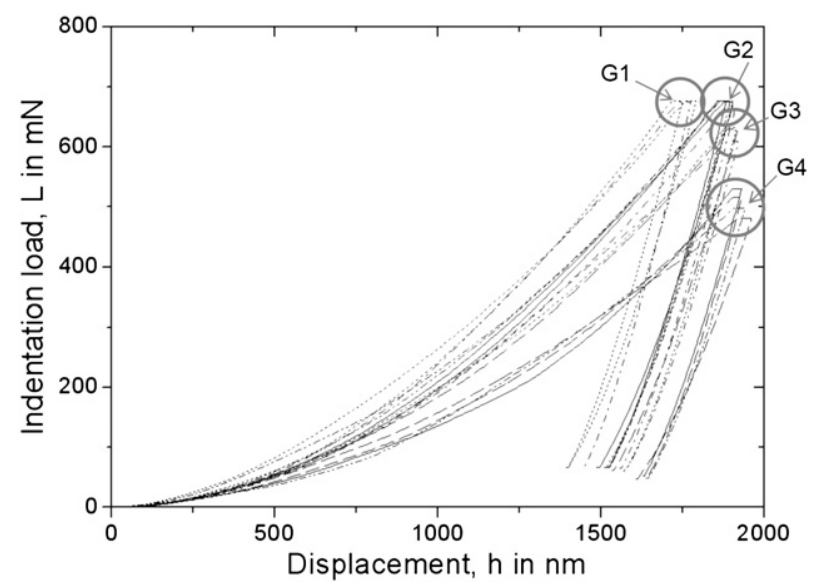

Fig. 3. Load-depth curves obtained by nanoindentation performed randomly at the surface of the $50 \%$ WC $-10 \mathrm{Co}-4 \mathrm{Cr} / 50 \%$ Colmonoy 88 coating.

particles rich in $\mathrm{W}$, as well as star-like particles with less amounts of W. According to previous studies [33-35], the latter could be associated either with complex $\mathrm{W}$ and $\mathrm{Cr}$ carbides and/or borides, as well as carbo-borides or complex Ni and $\mathrm{W}$ borides. Region $\mathrm{C}$, on the other hand, was found to have a higher content of $\mathrm{W}$ and less $\mathrm{Ni}$, in comparison with zone B. It is constituted by small spherical particles with a mean size of less than $1 \mu \mathrm{m}$.

Regarding the regions that correspond to the $\mathrm{WC}-10 \mathrm{Co}-4 \mathrm{Cr}$ phase, it was determined that these present a continuous $\mathrm{Co}$ and $\mathrm{Cr}$ matrix, where small WC carbide particles, in the range of $1 \mu \mathrm{m}$, are present.

\subsection{Mechanical characterization of the coating by nanoindentation}

From the microstructural viewpoint, the coating is composed of WC-10Co-4Cr with a complex Ni base matrix containing $\mathrm{W}, \mathrm{Cr}, \mathrm{Si}, \mathrm{Fe}$ and $\mathrm{B}$, distributed in it. Then at a nanoscale measurement, the coating can be considered as very heterogeneous. As a consequence, the values of the mechanical properties can vary to a large extent, depending on the nature and size of the particles located under the indented material, i.e. the proportion of the matrix, single phase, unmelted particles and hard particles, which can be associated with the presence of defects such as pores or inter-lamellar cracks [35,36]. For this reason, 20 indentation experiments were performed randomly at the surface of the coating. $25 \%$ of the indentation curves presented irregularities, which were associated with the defects present in the indented volume of the coating. As a result, the corresponding values of the mechanical properties

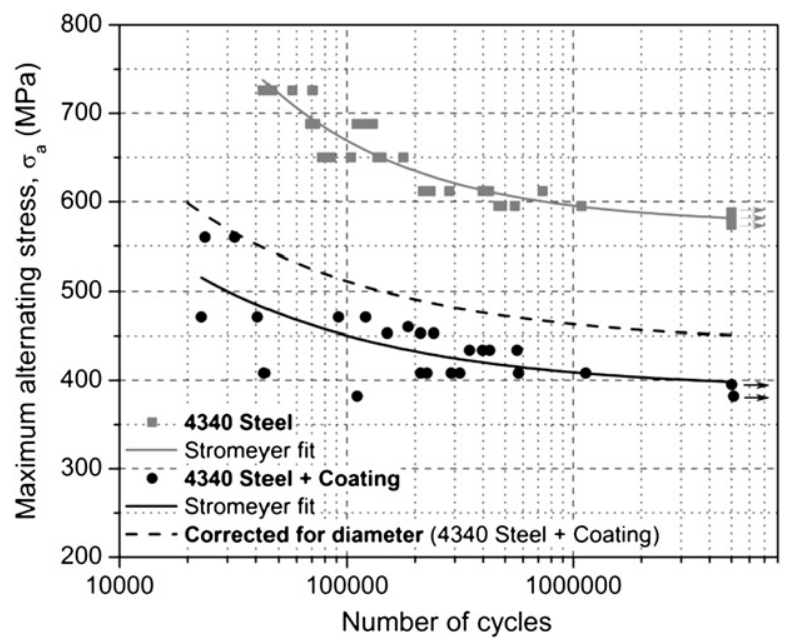

Fig. 4. Number of cycles to fracture as a function of the maximum alternating stress for the uncoated and coated substrate. in such a situation have not been considered in characterizing the coating. All the other curves were collected and are presented in Fig. 3.

As can be seen in the above figure, the load-depth curves are not superimposed due to the heterogeneity of the indented material. However, these have been separated into four main groups (G1, G2, G3 and G4), which can be associated with the different natures of the indented materials. Firstly, the indentation curves, which correspond to the lowest indentation depths reached at the same maximum applied load, can be associated with the hardest phases of the coating, probably carbides and/or borides. The other indentation curves attained lower maximum applied loads with the same maximum displacements of the indenter.

Thus, a number of curves are located around $600 \mathrm{mN}$ for the maximum indentation load and another group, around $500 \mathrm{mN}$. In this situation, it is obvious that the global hardness obtained at $500 \mathrm{mN}$, correspond to the softer phases, probably the matrix. It is important to point out that in Fig. 3, the first data points corresponding to $30 \mathrm{~nm}$ of displacement are not presented since opposite variations were observed, which could not be given any physical meaning. In fact, it is believed that this result was due to a rough approximation of the contact area calculation (polynomial law) due mainly to the rounded tip effect of the indenter and, to a lesser degree, to the surface roughness of the coating.

\subsection{Fatigue behavior of the coated system}

Fig. 4 illustrates that the Wöhler curve of the coated steel is below the curve that corresponds to the uncoated substrate, which indicates that the presence of the coating gives rise to a significant fatigue debit of the substrate, in the range of $\sim 33 \%$. Also, the fatigue limit $\left(\sigma_{L}\right)$ of the uncoated steel computed from the Stromeyer equation was found to be $\sim 575 \mathrm{MPa}$, whereas that of the coated system was $\sim 390 \mathrm{MPa}$, which represents a decrease of $32 \%$. If the Wöhler curve of the coated substrate is corrected for diameter effects, as shown also in the above figure, taking into consideration that for design purposes the coating is not considered as a load-carrying element of the coated system, the decrease in fatigue strength would be $\sim 25 \%$.

In order to explain the decrease in fatigue strength of the coated system it is necessary to analyze the fracture surface and crack sequence of the coated steel specimens. Thus, Fig. 5 illustrates the general fracture surface of a fatigue sample tested at $410 \mathrm{MPa}$, which failed after 1,134,800 cycles. At the region identified as 01, a crack initiation site can be clearly observed, located near the periphery of the specimen, from which the crack propagated throughout the crosssection of the sample, leaving behind a relatively flat surface. Also, at $180^{\circ}$ of the site 01 , a relatively rough surface can be seen, which corresponds to the ductile fracture zone (DFZ). In this zone, where

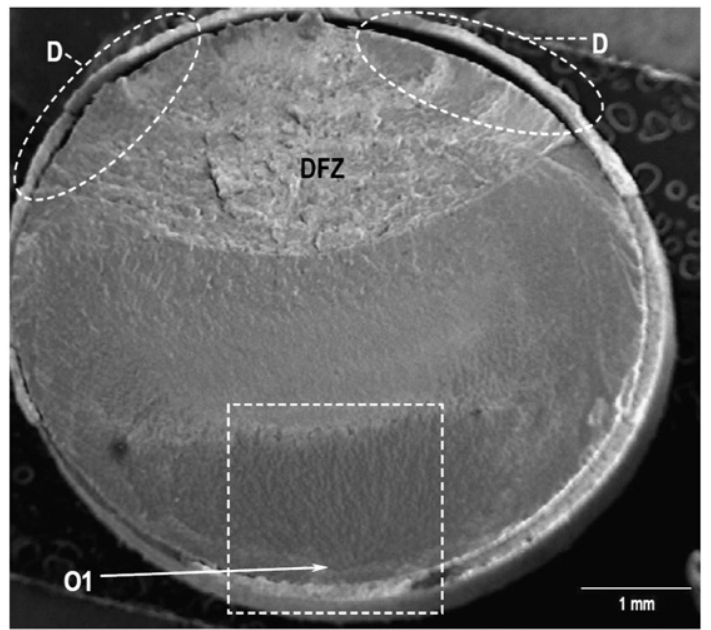

Fig. 5. SEM (SE) photomicrograph of the general fracture surface of a specimen tested at $410 \mathrm{MPa}$, which failed at $1,134,800$ cycles. 

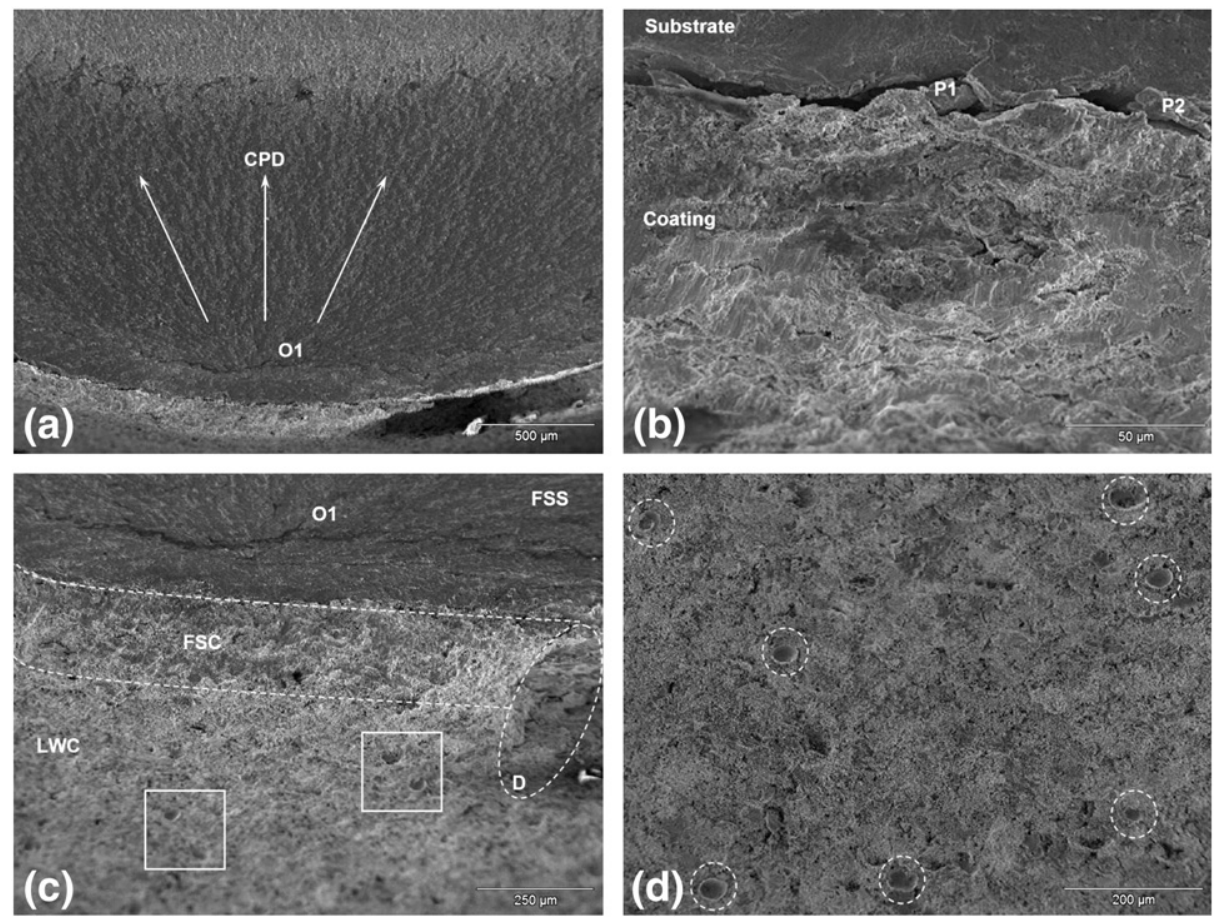

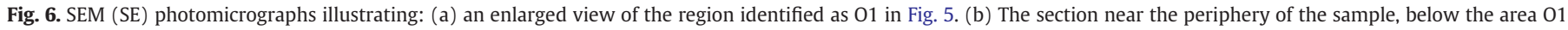
(c) Lateral view of the region enclosed by the rectangle in Fig. 5. (d) Detailed view of the lateral wall of the coating shown in Fig. 6c.

the final fracture occurred, a number of secondary cracks can be observed at the substrate-coating interface, which gave rise to the delamination of the coating, identified as D in the figure.

Fig. 6a illustrates at a higher magnification the region identified as 01 in Fig. 5. The radial markings, which originate at 01 indicate the crack propagation direction (CPD) along the fracture surface, as shown by the arrows on the photomicrograph. The radial markings converge to a point on the periphery of the sample located at the sub-surface of the substrate, which could be associated with the presence of a MnS inclusion and which would correspond to the nucleation site 01. Fig. $6 \mathrm{~b}$ illustrates an area close to the region 01 and to the periphery of the sample, in which the fracture surfaces of the coating and substrate can be clearly observed, as well as the presence of sharp alumina particles (P1 and P2) at the substrate-coating interface. On the other hand, Fig. $6 \mathrm{c}$ illustrates a simultaneous view of the fracture surface of the substrate (FSS) and coating (FSC), as well as the lateral wall of the coating (LWC), where some delamination (D) of the coating is observed. Fig. 6d shows a magnified view of the defects observed on the surface and indicates that these could be associated with unmelted or re-melted particles of the coating removed from this, possibly during cyclic loading.

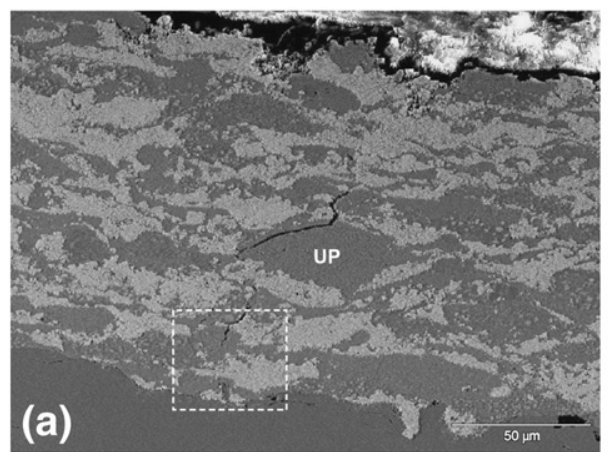

Finally, Fig. 7a illustrates a cross-section view normal to the fracture surface of the specimen, where again it can be clearly observed that the thickness of the coating is $130 \pm 20 \mu \mathrm{m}$. Also, a primary fatigue crack, which propagates close to an unmelted Colmonoy particle (UP), normal to the maximum alternating stress applied to the system, can be seen. The crack seems to have been nucleated at the middle section of the coating and propagates toward the substratecoating interface (Fig. 7b) through the Colmonoy-rich phases and boundaries between both the Colmonoy and WC-Co-Cr particles.

Regarding the fatigue sample tested at $470 \mathrm{MPa}$, which failed at 120,800 cycles and shown in Fig. 8, multiple fracture steps (FS) associated with different crack initiation sites could be observed, contrary to the specimen tested at a lower maximum alternating stress. The DFZ appears to be displaced toward the periphery of the sample. A number of secondary cracks both in the substrate (SCS) and the coating (SCC) can also be seen, as well as the delamination of the coating from the substrate. As expected, at this higher alternating stress, the crack propagation zone on the fracture surface is shorter than that observed for the sample tested at $410 \mathrm{MPa}$.

Fig. 9a illustrates a detailed view of the fracture steps (FS) present on the fracture surface. Such steps are formed as a result of the

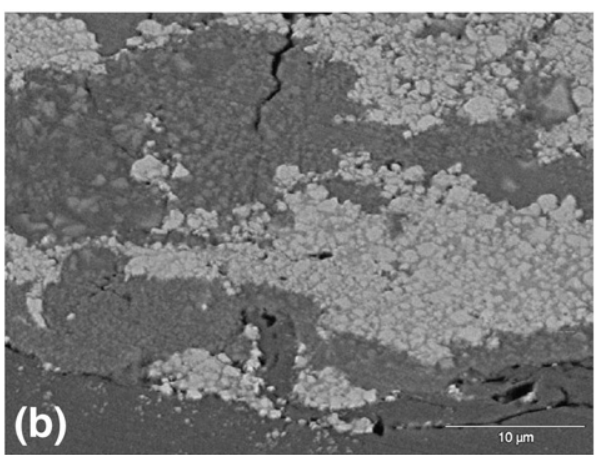

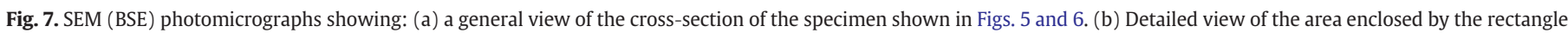
in Fig. 7a. 


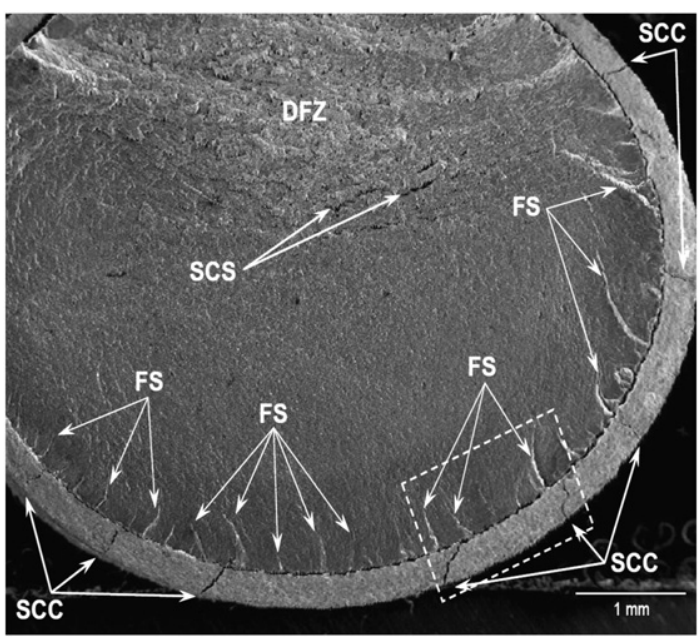

Fig. 8. SEM (SE) photomicrograph of the general fracture surface of a sample tested at $470 \mathrm{MPa}$, which failed at 120,800 cycles.

intersection of different fatigue cracks, which propagate simultaneously on different planes. Within such steps, a number of radial markings can be clearly seen, which seem to be associated with alumina particles (P1), as shown in detail in Fig. 9b, corresponding to a magnified view of the area indicated in Fig. 9a. Such sharp large alumina particles remain embedded at the substrate surface after grit blasting and become discontinuities, which hinder the adhesion of the coating and promote its delamination.

Fig. 9c, on the other hand, illustrates the lateral wall of the specimen (LWC), together with the fracture surface of both the coating (FSC) and substrate (FSS), where a number of secondary fatigue cracks, parallel to the specimen axis, can be observed. This unexpected cracking pattern could be due to the heterogeneity and relatively high roughness of the coating, with regions of limited adhesion and/ or cohesion. The above figure also shows the presence of craters or re-melted particles located on the lateral wall of the sample.

A cross-section view of the coated system, shown in Fig. 9d, illustrates the presence of a primary crack, which has propagated through the entire coating thickness and has bifurcated at the substrate-coating interface, giving rise to the delamination of the coating. As in the case analyzed above, the fatigue crack seemed to propagate preferentially along the lamella boundaries between the Colmonoy and $\mathrm{WC}-\mathrm{Co}-\mathrm{Cr}$ particles. This fact suggests a lack of adhesion and/or cohesion between these materials, which favors crack propagation along such boundaries. However, in some cases it has been observed that fatigue cracks could also propagate through the Ni-rich phases depleted of sub-micrometric second-phase particles, due to their low elastic modulus and hardness.

\section{Discussion}

Some representative curves have been drawn from Fig. 3, for analyzing the hardness and the elastic modulus variation as a function of the indentation displacement into the material. Fig. 10 represents the contact hardness and the elastic modulus variation as a function of the indenter displacement into the coating associated with the selected and representative indentation curves of each group (G1, G2, G3 and G4), as indicated in Fig. 3. As shown in Fig. 10a and b, the maximum values for the mechanical properties are obtained at the beginning of the loading curve, that is to say, at the outer surface of the coating, when the indenter crosses a hard particle corresponding to the WC.

The elastic modulus value obtained is equal to $550 \mathrm{GPa}$, in agreement with the value reported by Hyun et al. [37], whereas the contact hardness value of WC was found to be $35 \mathrm{GPa}$. Since the hard particles have low dimensions in comparison with the indenter displacement, the material surrounding the particles has a significant effect on the hardness measurement. As a result, a fast decrease in hardness and elastic modulus are observed, which tend to achieve constant values of $10 \mathrm{GPa}$ and 250 GPa for the hardness and the elastic modulus, respectively. These values are very similar to those reported by Santana et al. [38,39].
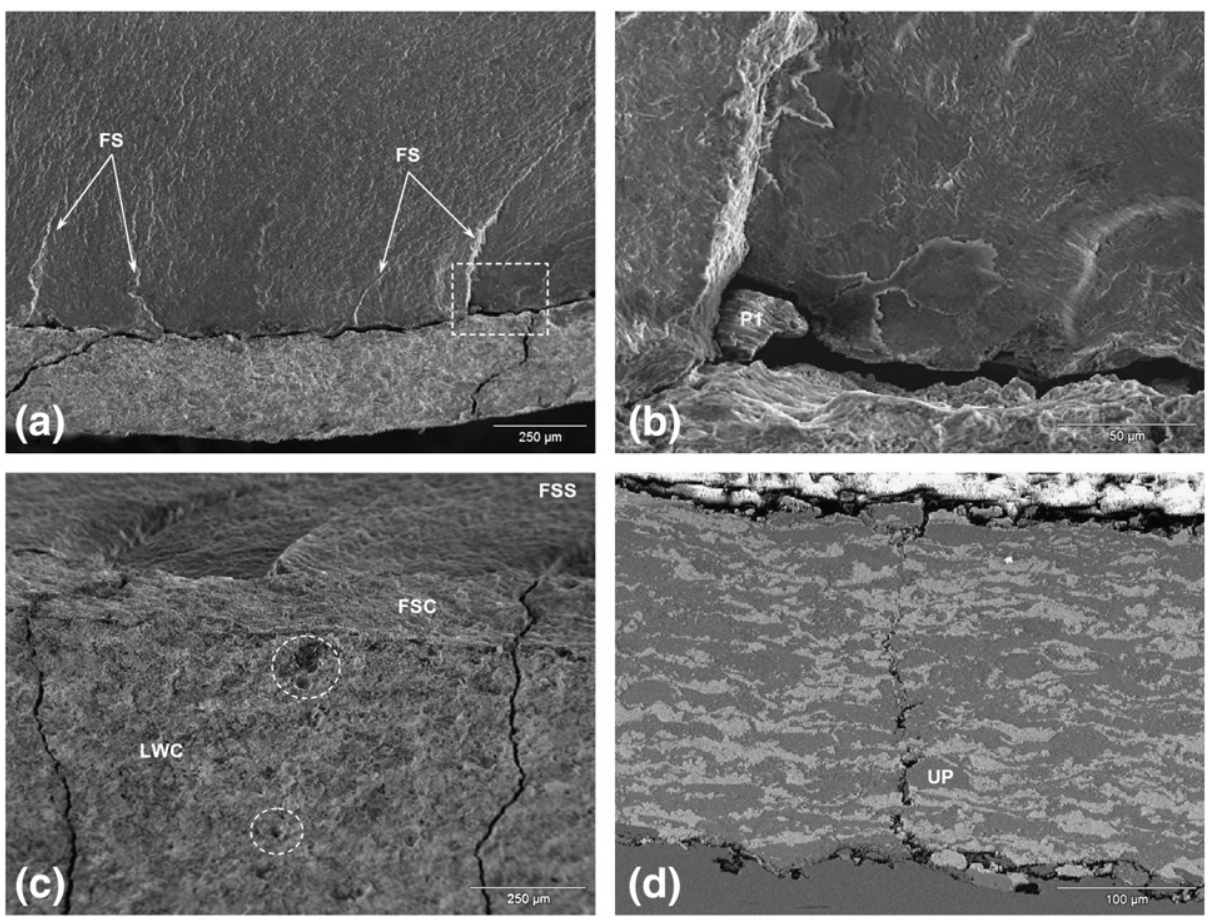

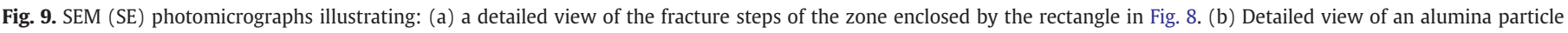

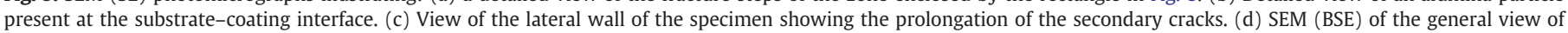
the cross-section of the sample shown in Fig. 8. A primary crack originated from the coating surface has propagated through the coating thickness up to the interface. 

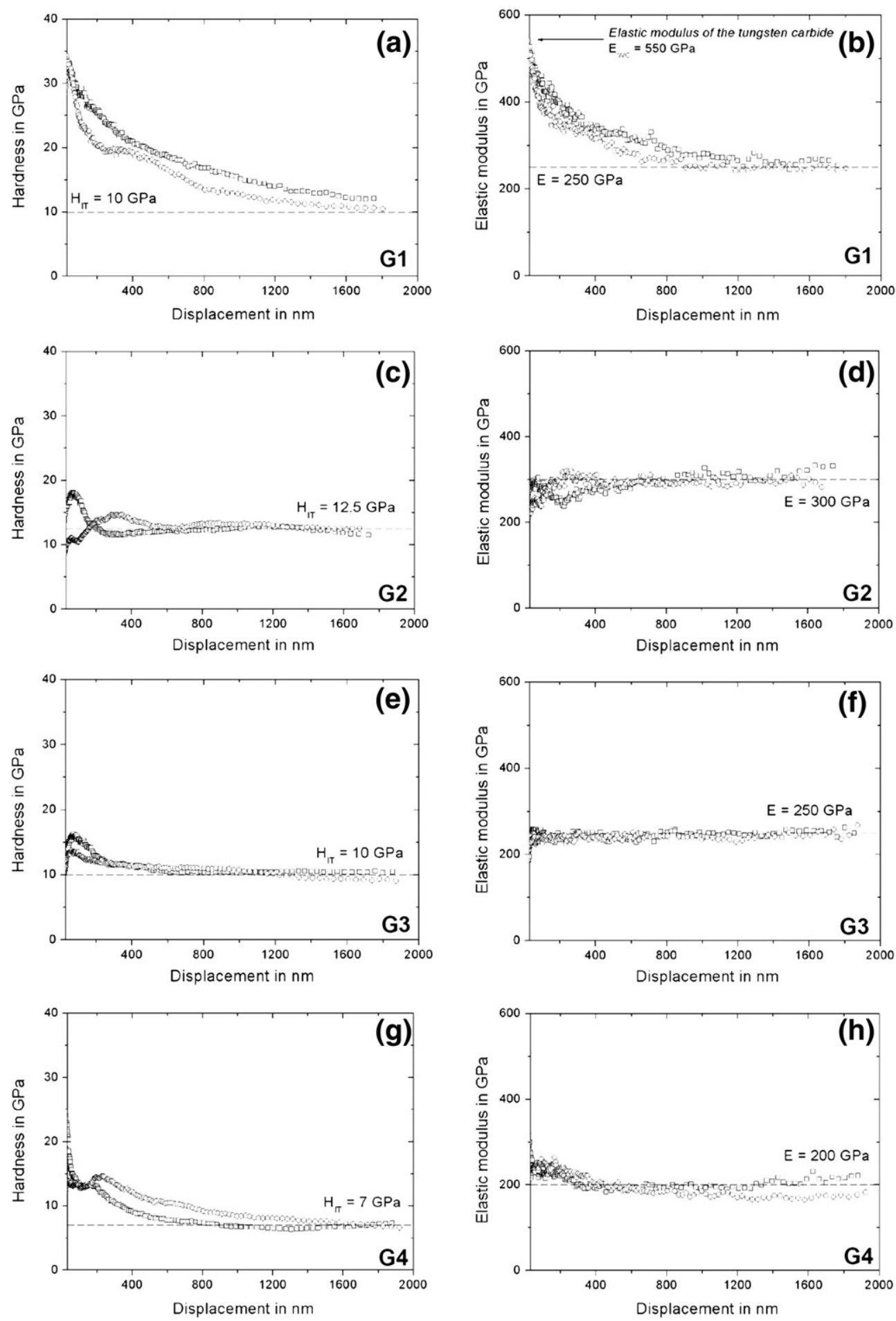

Fig. 10. Hardness (left side) and elastic modulus (right side) determined by means of the analysis of a series of curves for each group.

It is important to note that the bulging observed on the hardness variation (Fig. 10a) is probably due to the presence of very small second-phase hard particles, since the hardness value is much lower than $35 \mathrm{GPa}$. The lowest values for the mechanical properties shown in this figure are also observed as constant values in Fig. 10e and $f$ over the entire loading of the indenter. Only a hardness increase is observed over the first $200 \mathrm{~nm}$ of the indenter displacement. These mechanical properties can be associated with region $\mathrm{B}$, rich in $\mathrm{Ni}$ and $\mathrm{Cr}$, identified in Fig. 2c. For this region, the elastic modulus varies from 150 to $250 \mathrm{GPa}$, depending on the constitutive elements of the matrix.
It can be observed that the lowest values of $\mathrm{H}_{\mathrm{IT}}$ and $\mathrm{E}$ shown in Fig. $10 \mathrm{~g}$ and h, i.e. $7 \mathrm{GPa}$ for the contact hardness and $200 \mathrm{GPa}$ for the elastic modulus, are very similar to those reported by La Barbera et al. [36]. The hardness variations, which can be observed at the beginning of the indentation curves, are due to the presence of hard particles since the value tends to that characteristic of the mechanical properties of the WC (Fig. 10g). On the other indentation curves, a change is also visible on the first 200 or $400 \mathrm{~nm}$.

The increase or decrease of the hardness value is also associated with the presence of WC as hard particles, but the values attained are much lower than those of this compound due to the small size 


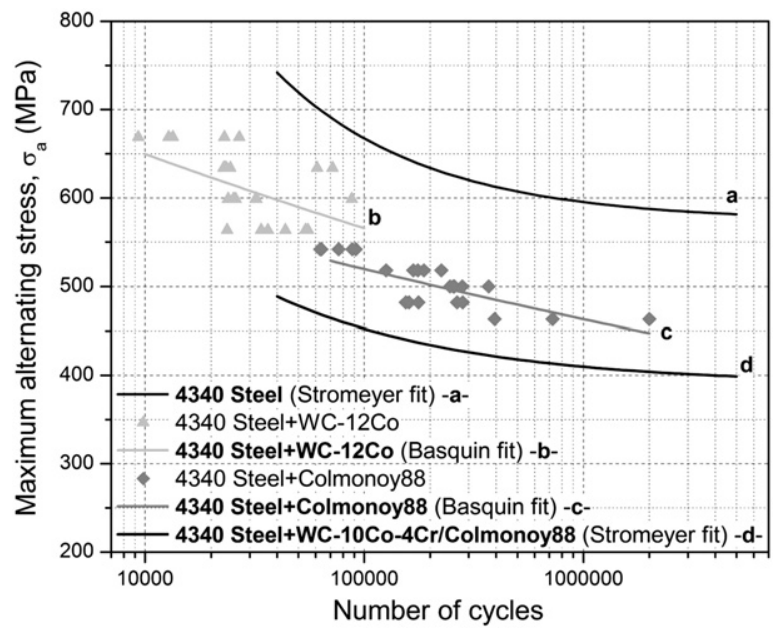

Fig. 11. Wöhler curves for the uncoated SAE 4340 substrate, as well as those coated with WC-12Co, Colmonoy 88 and WC-10Co-4Cr/Colmonoy 88 , deposited by HVOF thermal spray.

of this particle and the influence of the matrix around the latter. In addition, an interesting result is shown in Fig. 10c and d, in which a constant contact hardness and elastic modulus are obtained, i.e. $12.5 \mathrm{GPa}$ and $300 \mathrm{GPa}$, respectively. These can be associated with region C, identified in Fig. 2c, where the largest content of $\mathrm{W}$ is seen, as well as the presence of sub-micrometric second phase particles. Then, these values are associated with a homogeneous phase at the scale of measurement. It is likely that these mechanical properties correspond to the mechanical properties of various borides, which can be identified in the coating.

Finally, Fig. 11 illustrates a comparison of the fatigue behavior of the coated system investigated in this work and other thermally sprayed coated systems which involve the same substrate steel. Thus, three additional Wöhler curves are presented, which include those of the uncoated substrate, the substrate coated with Colmonoy 88 [22] and the substrate coated with WC-12Co [23]. It can be clearly observed that the deposition of these thermal spray coatings onto the surface of the 4340 steel substrate gives rise to a decrease in the fatigue strength of the substrate. The smallest fatigue debit seems to be associated with the deposition of WC-12Co, followed by the deposition of Colmonoy 88 and finally that which involves the powder mixture of WC-10Co-4Cr/Colmonoy 88. Fig. 12 illustrates the Wöhler curves obtained from the fatigue data reported by Voorwald et al. [4], regarding axial fatigue tests $(R=0.1)$ of uncoated and coated specimens of AISI 4340 with a WC $-10 \mathrm{Co}-4 \mathrm{Cr}$ deposited by HVOF. Such

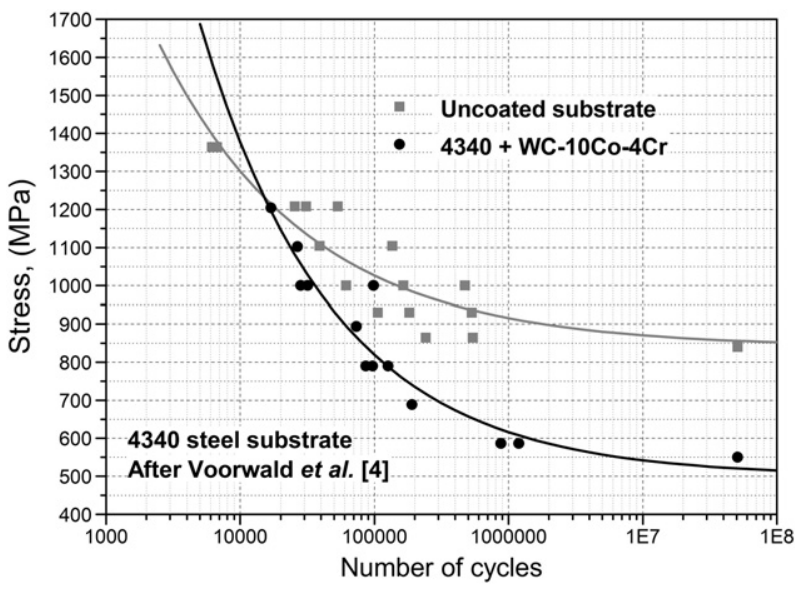

Fig. 12. Wöhler curves corresponding to the uncoated and coated specimens of the AISI 4340 steel with a WC-10Co-4Cr coating. The experimental data was taken from the work of Voorwald et al. [4]. results indicate that the deposition of the coating $170 \mu \mathrm{m}$ in thickness gives rise to a decrease in the fatigue strength of the substrate of up to approximately $40 \%$, depending on the number of cycles to fracture. As the number of cycles to fracture increases, the fatigue debit produced by the coating also increases.

There are many factors that could affect the fatigue performance of these coated systems, which include: grit blasting, spraying gun, spraying distance, flux of the gases employed and thickness and roughness of the coatings, among others. The largest fatigue debit determined in the present work, could be attributed to the larger spraying distance that was employed in coating this system $(\sim 406 \mathrm{~mm})$, in comparison with the other two systems for which the spraying distance was somewhat smaller $(\sim 380 \mathrm{~mm})$. The other deposition parameters were maintained constant for the three coated systems. In this way, as the spraying distance increases, it is likely that the particles reach the substrate or the successive deposited layers at a lower temperature, as shown in Figs. 6d, 7a and 9c and $d$. In the above figures, a number of unmelted particles and craters, which possibly correspond to re-solidified particles, could be observed.

Another important factor could be the use of different powders, which could compromise the adhesion and/or cohesion among them, giving rise to the presence of weak boundaries, which would favor the propagation of fatigue cracks, as shown in the fractographic analysis that has been conducted. Also, the nanoindentation characterization of the coating showed that there are significant differences in the load-carrying capability of the coating due to the differences in the elastic modulus and hardness. Such differences would enhance the propagation of cracks through the Ni-rich regions of the coating, which are depleted of sub-micrometric second phase particles, which also have a lower hardness and elastic modulus.

\section{Conclusions}

The deposition of a $50 \%$ WC-Co- $\mathrm{Cr} / 50 \%$ Colmonoy 88 coating onto a SAE 4340 steel substrate by thermal spraying gives rise to a deposit with a heterogeneous microstructure and therefore, with different mechanical properties, as shown by the nanoindentation characterization that has been conducted. The coated system, with a coating $130 \pm 20 \mu \mathrm{m}$ in thickness, exhibits a decrease in fatigue strength of $\sim 30 \%$, in comparison with the uncoated substrate. The computed fatigue limit according to the Stromeyer relationship (390 MPa) is about $32 \%$ less than that of the uncoated substrate ( $575 \mathrm{MPa})$. This decrease in fatigue properties for the coated system has been attributed both to the presence of stress concentrators at the substratecoating interface and to the properties of the coating. The fractographic analysis of the tested specimens suggests that nucleation of fatigue cracks could occur simultaneously at both the substrate-coating interface and the outer surface of the coating. In the first case, nucleation of fatigue cracks would be associated with the irregularities that exist at the interface and the presence of alumina particles, which act as stress concentrators. In the second case, nucleation of cracks would be related to the presence of craters and the high roughness of the coating. Propagation of fatigue cracks through the coating thickness occurs preferentially along the particle boundaries that comprise the coating, particularly through the Ni-rich particles.

\section{Acknowledgments}

The present investigation has been carried out with the support of the Scientific and Humanistic Development Council of the Universidad Central de Venezuela (CDCH-UCV) through Project PI-08-7823-2009/2. Professor La Barbera-Sosa acknowledges the assistance of D. Zambrano and T. Mujica for conducting the fatigue experiments. Professor PuchiCabrera gratefully acknowledges the financial support of the Conseil Régional Nord-Pas de Calais, France, through the International Chair Program 2011. 


\section{References}

[1] T. Khaled, Report \# ANM-112N-01-02. Lakewood, CA, January 2002, p. 24.

[2] A. Buffoli, M. Pesetti, in: C.C. Berndt, S. Sampath (Eds.), Proc. 8th Nat. Thermal Spray Conf.: Thermal Spray Science and Technology, ASM International, Materials Park, OH, USA, 1995, p. 671.

[3] A. Ibrahim, C.C. Berndt, Mater. Sci. Eng., A 456 (2007) 114.

[4] H.J.C. Voorwald, R.C. Souza, W.L. Pigatin, M.O.H. Cioffi, Surf. Coat. Technol. 190 (2005) 155.

[5] Hard Chrome Alternatives Team (HCAT), Validation of HVOF Thermal Spray Coatings as Replacements for Hard Chrome Plating on Hydraulic/Pneumatic Actuators, August 2, 2004

[6] B. Sartwell, K. Legg, J. Sauer, Validation of WC/Co and WC/CoCr HVOF Thermal Spray Coatings as a Replacement for Hard Chrome Plating On Aircraft Landing Gear. U.S. Hard Chrome Alternatives Team (HCAT) and Canadian Hard Chrome Alternatives Team (CHCAT), November 21, 2002.

[7] B.D. Sartwell, P.M. Natishan, I.L. Singer, K.O. Legg, J.D. Schell, J.P. Sauer, Proc. of the 1998 Aerospace/Airline Plating and Metal Finishing Forum, (San Antonio, TX, 24-26 March 1998), 1998, p. 97.

[8] M.P. Nascimento, R.C. Souza, W.L. Pigatin, H.J.C. Voorwald, Int. J. Fatigue 23 (2001) 607.

[9] M.P. Nascimento, R.C. Souza, I.M. Miguel, W.L. Pigatin, H.J.C. Voorwald, Surf. Coat Technol. 138 (2001) 113.

[10] R.T.R. McGrann, D.J. Greving, J.R. Shadley, E.F. Rybicki, T.L. Kruecke, B.E. Bodger, Surf. Coat. Technol. 108-109 (1998) 59.

[11] K. Padilla, A. Velázquez, J.A. Berríos, E.S. Puchi-Cabrera, Surf. Coat. Technol. 150 (2002) 151.

[12] T.N. Rhys-Jones, T.P. Cunninghan, Surf. Coat. Technol. 42 (1990) 13.

[13] H.J.C. Voorwald, L.F.S. Vieira, M.O.H. Cioffi, Procedia Eng. 2 (2010) 331.

[14] G.S. Junior, H.J.C. Voorwald, L.F.S. Vieira, M.O.H. Cioffi, R.G. Bonora, Procedia Eng. 2 (2010) 649.

[15] R.C. Souza, H.J.C. Voorwald, M.O.H. Cioffi, Surf. Coat. Technol. 203 (2008) 191.

[16] J.G. La Barbera-Sosa, Y.Y. Santana, C. Villalobos-Gutiérrez, S. Cabello-Sequera, M.H. Staia, E.S. Puchi-Cabrera, Surf. Coat. Technol. 205 (2010) 1137.

[17] J.G. La Barbera Sosa, Y.Y. Santana Méndez, M.H. Staia, E.S. Puchi Cabrera, Acta Microsc. 18 (1) (2009) 39.
[18] E.S. Puchi-Cabrera, M.H. Staia, J. Lesage, D. Chicot, J.G. La Barbera-Sosa, E.A. Ochoa-Pérez, Surf. Coat. Technol. 201 (2006) 2038.

[19] E.S. Puchi-Cabrera, J.A. Berrios, J. Da-Silva, J. Nunez, Surf. Coat. Technol. 172 (2-3) (2003) 128

[20] F. Oliveira, L. Hernandez, J.A. Berrios, C. Villalobos, A. Pertuz, E.S. Puchi Cabrera, Surf. Coat. Technol. 140 (2001) 128.

[21] V. Higuera-Hidalgo, J. Belzunce-Varela, A. Carriles-Menéndez, S. Poveda-Martínez, Surf. Eng. 17 (6) (2001) 512.

[22] L. Hernández, F. Oliveira, J.A. Berrios, C. Villalobos, A. Pertuz, E.S. Puchi-Cabrera, Surf. Coat. Technol. 133-134 (2000) 68.

[23] K. Chirinos, Final Report, School of Mechanical Engineering, Faculty of Engineering, Universidad Central de Venezuela, 2003.

[24] H. Akebono, J. Komotori, M. Shimizu, Int. J. Fatigue 30 (2008) 814.

[25] G.D. Quinn, P.L. Patel, I. Lloyd, J. Res. Nat. Inst. Stand. Technol. 107 (2002) 299

[26] H. Bückle, Metallurgical Review, 4, Institute of Metals, London, 1959, p. 49.

[27] H. Bückle, in: J.H. Westbrook, H. Conrad (Eds.), The Science of Hardness Testing and Its Research Applications, ASME, Metal Park, OH, 1973, p. 199.

[28] X. Cai, H. Bangert, Thin Solid Films 264 (1) (1995) 59.

[29] Y. Sun, T. Bell, S. Zheng, Thin Solid Films 258 (1-2) (1995) 198

[30] T. Chudoba, N. Schwarzer, F. Richter, Surf. Coat. Technol. 154 (2-3) (2002) 140.

[31] F. Cleymand, O. Ferry, R. Kouitat, A. Billard, J. von Stebut, Surf. Coat. Technol. 200 (1-4) (2005) 890

[32] C.E. Stromeyer, Proc. R. Soc. London Ser. A 90 (1914) 411.

[33] M. Rodríguez, M. Sc. Thesis, School of Metallurgical Engineering and Materials Science, Faculty of Engineering, Universidad Central de Venezuela, Caracas, Venezuela, 2002, pp. 85

[34] L. Gil, M.H. Staia, Surf. Coat. Technol. 120-121 (1999) 423.

[35] J.G. La Barbera-Sosa, Y.Y. Santana, M.H. Staia, D. Chicot, J. Lesage, J. Caro, G Mesmacque, E.S. Puchi-Cabrera, Surf. Coat. Technol. 202 (2008) 4552

[36] J.G. La Barbera-Sosa, Y.Y. Santana, E. Moreno, N. Cuadrado, J. Caro, P.O. Renault, E. Le Bourhis, M.H. Staia, E.S. Puchi-Cabrera, Surf. Coat. Technol. 205 (2010) 1799.

[37] H.C. Hyun, M. Kim, J.H. Lee, H. Lee, Mech. Mater. 43 (2011) 313.

[38] Y.Y. Santana, J.G. La Barbera-Sosa, J. Caro, E.S. Puchi-Cabrera, M.H. Staia, Surf. Eng. 24 (5) (2008) 374.

[39] Y.Y. Santana, J.G. La Barbera-Sosa, A. Bencomo, J. Lesage, D. Chicot, E. Bemporad, E.S. Puchi-Cabrera, M.H. Staia, Surf. Eng. 28 (4) (2012) 237. 